\title{
RENT-SEEKING DECISIONS OF THE MAIN PARTICIPANTS IN CONSTRUCTION PROJECTS BASED ON EVOLUTIONARY-GAME AND SYSTEM DYNAMICS
}

\author{
Weiwei ZUO1, Qiankun WANG ${ }^{2}$, Peng $\mathrm{LI}^{3 *}$ \\ ${ }^{1}$ School of Civil Engineering, Architecture and Environment, Hubei University of Technology, Wuhan, China \\ ${ }^{2}$ School of Civil Engineering and Architecture, Wuhan University of Technology, Wuhan, China \\ ${ }^{3}$ School of Entrepreneurship, Wuhan University of Technology, Wuhan, China
}

Received 1 July 2020; accepted 3 November 2021

\begin{abstract}
The performance of a construction project can be severely harmed by its participants' rent-seeking. In order to prevent such attempt, this research integrates the evolutionary game theory with system dynamics method to simulate the impact of the change of some factors that may cause/reduce rent-seeking. Based on the analysis of the behavioral characteristics and interactive relationships of the main participants (the owner, supervisor, and contractor), an evolutionary game model is constructed and simulated with the method of system dynamics based on the replication dynamic equation of the mixed strategy solution of the three-party static game model. By assigning the parameters of project scale, supervision likelihood, supervision success rate, supervision cost, and penalty intensity, the interaction mechanism of the participants on each factor is revealed through a case-based simulation. The results show that the impacts of these factors on participants' rent-seeking decisions are significantly different. Furthermore, some management suggestions are provided to prevent rent-seeking for project owner according to the research conclusions. This research can help the project owners take proper measures to prevent rent-seeking of the supervisors and the contractors to improve the performances of the projects.
\end{abstract}

Keywords: project management, project participants, rent-seeking, evolutionary game, system dynamics.

\section{Introduction}

Corruption can hinder the social and economic development of human societies worldwide (Snaith \& Khan, 2008). With a large number of participants, a big amount of investment, a long period of construction and a wide range of influence, the construction projects are conducive to the stability and prosperity of the national economy and society. However, these features also make them vulnerable to corruptions. Corruption behaviors are common in the field of construction (Boudreaux et al., 2018; GoldieScot, 2008; Kyriacou et al., 2015; Le et al., 2014). With the continued economic growth and urbanization worldwide, an increase in corruption has yielded in infrastructure and urban construction projects (Ameyaw et al., 2017; Kenny, 2009). Corruption of construction may occur in any phase of a project (Sohail \& Cavill, 2008); such as project initiation, planning and design, bidding and construction, and operation and maintenance (Chan \& Owusu, 2017; Tabish \& Jha, 2011; Zhang et al., 2017). Corruption is an extremely significant risk that greatly impacts score management tasks in construction projects, particularly in developing countries (Deng et al., 2013; Fernandez-Dengo et al., 2013). Some efforts have been made to investigate causes of corruption in the construction industry (Brown \& Loosemore, 2015; Owusu et al., 2017). Most of the corruptions are caused by the rent-seeking (Di \& Ji, 2012). The project participants' rent-seeking behavior, which is non-productive, can lead to unfair competition, resource unreasonably distribution and disharmony of the mutual-value-realization among the stakeholders in a project (Iqbal \& Daly, 2014). Therefore, it is very important to prevent construction rent-seeking to guarantee the efficient project management and delivery. In this research, a new approach, combining the system dynamics method with evolutionary game theory, is used to analyze and simulate the impact of rent-seeking decisions among participants.

${ }^{*}$ Corresponding author. E-mail: 542814313@qq.com

Copyright $\odot 2022$ The Author(s). Published by Vilnius Gediminas Technical University

This is an Open Access article distributed under the terms of the Creative Commons Attribution License (http://creativecommons.org/licenses/by/4.0/), which permits unrestricted use, distribution, and reproduction in any medium, provided the original author and source are credited. 


\section{Literature review}

\subsection{Rent-seeking in construction}

As the rent-seeking among project participants is the main concern of the research, the research on rent-seeking is reviewed. Gordon Tullock, who is the developer of the rent-seeking theory, defined the term rent-seeking as "an attempt to obtain economic rent by manipulating the social or political environment in which economic activities occur, rather than by creating new wealth" (Tullock, 2001, 2005). There are a lot of research focusing on some aspects and stages of the project participants' rent-seeking. Based on the prospective of economics, Wang et al. (2008) categorized the reason of rent-seeking of engineering supervisors into subjective and objective factors. Wu and Peng (2013) discussed the rent-seeking between the owners and the contractors at the tendering stage and the rent-seeking conspiracy of contractors and supervisors. Liu et al. (2010) adopted classic Tullock model to analysis the land rentseeking games of the real-estate developers. Wang and Cheng (2013) studied the rent-seeking theory based on a comparison among current construction supervision mode, PM mode and hybrid mode. Mei et al. (2017) suggested that BIM and IPD have a positive impact on rentseeking activities of construction projects. A simulation technology was run to study the interactions among the stakeholders to observe the impact of rent-seeking on the related benefits and safety statuses (Feng et al., 2019). Qin (2017) analyzed the rent-seeking from the prospective of legislation, regulation, mechanism and motivation and gave his suggestions on how to prevent such behaviors.

\subsection{Evolutionary game theory}

Evolutionary game theory is one of the most fruitful frameworks for studying evolution in different disciplines, ranging from Biology to Economics (Roca et al., 2009). This research integrates the evolutionary game theory with system dynamics method to simulate various factors that may cause/reduce rent-seeking. So, the research status of game theory and system dynamics applied to analyze the rent-seeking is reviewed. Li (2009) used game theory to uncover the inner motivation of rent-seeking decisions in each stage of the construction process. Feng et al. (2015) took the construction safety supervision as the research target and proposed an evolutionary game model of the rent-seeking decisions among bounded rationality participants. The trilateral static game model is established to analysis the relationships among three participants (Huang \& Chen, 2012; Shiwei et al., 2006). Xiang and Ren (2010) established a trilateral behavior game theory of general and public projects and suggested that the rent-seeking can be prevented by establishing a refined construction management regulation, combining forward-supervision and afterward-punishment and integrating excitation and restraint mechanism. Considering the Information Asym- metry among the game process, Wang et al. (2005) established an incomplete information dynamic models among government. Guo et al. (2018) proposed a system dynamics model based on evolutionary game theory to describe the complex and dynamic interactions among tripartite stakeholders in China.

\subsection{Contributions and limitations of current research}

Overall, the fundamental interests of all participants in the construction project are consistent. Through the cooperation of all participants, the construction project is completed on schedule, on quality and on quantity, so as to ensure that the project is completed according to the established plan and take the project as the carrier to realize their respective interests. However, due to the asymmetric information, large investment in resources, long construction duration and lack of supervision of power in the construction of the project, as well as the fact that project participants are each an economic entity, in order to pursue the maximization of their own interests, the project corruption rent-seeking and collusion free-rider behavior and other behaviors are repeatedly prohibited (Di \& Ji, 2012). This would inevitably affect the quality, construction period, cost, safety and other objectives of the project, resulting in the loss of the owner's interests (Xiang et al., 2009). Unfair competition, unreasonable resource allocation and unequal cooperation mechanism caused by the above behaviors have become the restrictive factors for the success of construction projects.

Current research has covered various project participants including governments, tender agents, owners, supervisors, and contractors as well as various stages including project initialization, design, tendering and construction. Most of the participants only focus on the exterior impacts of a project such as government, public, supervision and bidding system. However, the inner impacts of a project have not been paid much attention to. In addition, based on the hypothesis of static gaming and perfect rationality, most researches cannot be applied to the long-term dynamic analysis of the behaviors from bounded rationality entities, which is the case of a construction engineering project. Last but not least, most researches try to get and furthermore analyze the solutions from the behavior entity game model, but their outcomes are not intuitivelyrepresented.

This research combines the evolutionary game theory with system dynamics method to simulate various factors that may cause/reduce rent-seeking. In order to get a more intuitive result of the dynamic process of the tripartite gaming, this research adopts a system dynamics software - Vensim, together with a case-based simulation to find the influence mechanism of rent-seeking in construction projects and furthermore provide management suggestions to prevent such rent-seeking. 


\section{Methodology}

There are many participants in construction project, and each participant can also form a consortium by several units. This paper mainly studies the influence mechanism of game behavior changes among different types of participants on the construction objectives and the interests of various participants in the project. Therefore, multiple participants of the same type in the construction project are classified according to categories and regarded as the same participants for research, regardless of the impacts of the diversification of participants. However, as the cooperative relationship of participants is different under different cooperation modes of projects, the composition of the crucial participants is related to the partnering models of projects, such as DBB, EPC, BOT et al. In this study, the content is based on the background of the traditional project management mode (Design-Bid-Build, DBB). In addition, this study focuses on the construction stage in DBB mode and the designer is not directly involved in the construction process unless the design alteration. So, the realization of the objectives and interests is mainly affected by the decision-making of the owners, contractors and supervisors. Meanwhile, in order to highlight the main influence mechanism of rent-seeking decisions, only the owners, supervisors and contractors who play a key role in the construction of the project are considered, while other participants such as suppliers are ignored.

The realization of project objectives is based on the changes of the behavior decisions of the owners, supervisors, contractors and other participants. The behavior of each subject is affected by its own behavior decisions and the behavior decisions of other subjects. Its essence is the dynamic process of continuous learning, analysis, decision-making and game of all participants. In the construction of engineering projects, the problems of the incomplete information of stakeholders involved in the project and the bounded rationality of participants are obvious. Therefore, bounded rational evolutionary game theory is an effective tool to analyze the rent-seeking decisions of engineering participants (Xie, 2007).

This research combines system dynamics method with evolutionary game theory to analyze and simulate the impact of rent-seeking of the participants. In order to get a more intuitive result of the dynamic process of the tripartite gaming, this research adopts a system dynamics software - Vensim, together with a case-based simulation to find the influence mechanism of rent-seeking in construction projects and furthermore provide management suggestions to prevent such behaviors.

The steps are as follows: first, the relationships among the three participants are described and hypothesis of evolutionary game theory are set according to the behavioral characteristics of the participants; second, a payoff matrix of the trilateral game is established and the payoff model of each participant is set up accordingly; third, the replicated dynamic equation is established in terms of the payoff model of the owner, supervisor and contractor, and

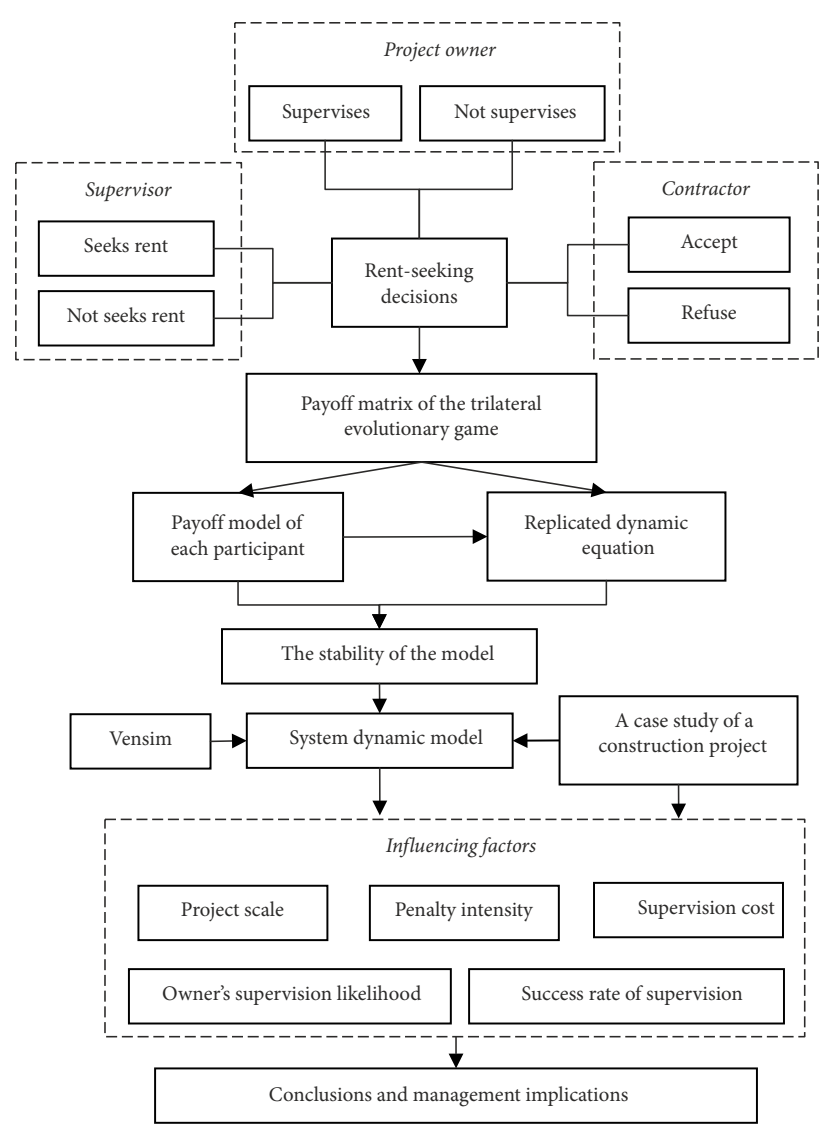

Figure 1. The research framework of rent-seeking game

the stability of evolutionary game of owner A, supervisor $\mathrm{B}$ and contractor $\mathrm{C}$ is analyzed respectively; fourth, the system dynamic model is established via Vensim software, and then the interactions among participants on each factor are revealed through a case-based simulation; finally, management suggestions are provided to prevent rentseeking for project owner. The framework of this research is presented in Figure 1.

\section{Behavioral characteristics and fundamental hypothesis}

\subsection{Behavioral characteristics and interactive relationships of the participants}

The profit seeking behavior of each subject and the change of its decision-making in the construction project will have an important impact on the project objectives, and will have a significant impact on the realization of the interests of other subjects in the construction project. The owner is direct investor in engineering projects. They usually want to obtain buildings with the lowest cost, the best use function and the shortest construction period. As an independent economic entity, in order to maximize their own interests, engineering construction contractors may violate professional ethics and make behaviors inconsistent with the contract. The supervisor supervises the quality, progress and cost of the project on behalf of the owner in the form of contract, but the supervisor is likely to col- 
lude with the contractor in pursuit of additional income. It will seriously affect the realization of project objectives and overall benefits and cause the loss of interests of the owner. In order to reduce the risk of engineering construction and ensure the realization of engineering construction objectives, the owner will inevitably strengthen supervision to prevent the occurrence of rent-seeking of contractor and supervisor. Therefore, the cooperation among the owner, contractor and supervisor is accompanied by a game and it runs through the whole process of project construction management.

In a construction project under traditional DBB mode, the interactive relationships of the owner, supervisor and contractor (project main participants) are as follows. The owner signs the construction contract with the contractor winning the bid so that the latter ones are responsible for the construction of the project. Meanwhile, the owner signs supervision contract with the supervisor to authorize him to supervise the projects. The contractor is under supervision of the supervisor although there is no direct contract relationship between them. Among the interactions, the supervisor and the contractor may conspire against the owner to obtain more benefit (illegal revenue) than those defined in the contract. In this situation, they two forms a cooperation gaming relationship and a rentseeking happens.

Based on the current situation and the behavior characteristics of the owner, supervisor and contractor involved in the construction project, it is known that: (1) neither the supervisor nor the contractor knows if the owner supervises them; (2) the owner has the right to choose to supervise them or not; (3) the owner does not know the rent-seeking without supervising, but it may not be detected even with supervising. In summary, the three participants form an incomplete information game.

\subsection{Fundamental hypothesis of evolutionary game}

In this research, the letters $\mathrm{A}, \mathrm{B}$ and $\mathrm{C}$ represent the owner, supervisor, and contractor, respectively. Additional cost occurs when the owner decides to supervise the other participants and this cost often increases with the scale of the project. Therefore, the supervision cost can be calculated as $\mathrm{d}^{*} \mathrm{P}$, where $\mathrm{P}$ is a value representing the scale of the project and $\mathrm{d}$ is the supervision cost ratio. The normal revenue of the owner is $\mathrm{V}$ and that of the supervisor, which is paid by the owner, is $\mathrm{e}^{\star} \mathrm{P}$, where e is the supervision fee ratio. The $\mathrm{d}$ and $\mathrm{e}$ are based on the historical statistic data. If a rent-seeking happens, the total revenue of the contractor is $\mathrm{R}(\mathrm{V}>\mathrm{R})$ and the supervisor gets a bribe of $\mathrm{k}^{\star} \mathrm{R}$ from the contractors, $0 \leq \mathrm{k} \leq 1$. Specific assumptions are as follows:

(1) There are two kinds of strategies for the owner, supervisor, and contractor each to choose from. The owner can choose to supervise or not; the supervisor can choose to invite the contractor to the rent-seeking conspiracy or not, the contractor can choose to accept the invitation or not.
(2) If the owner decides to supervise the supervisor and contractor, an additional cost of $\mathrm{d}^{*} \mathrm{p}$ is required. If the rent-seeking decisions are detected, a penalty is applied. The contractor shall pay $\mathrm{m}$ times of his illegal revenue $\left(m^{\star} R\right)$ and the supervisor should pay $n$ times of his illegal revenue $\left(n^{*} k^{\star} R\right)$.

(3) The likelihood of the owner's decision of supervision/ no supervision is $\mathrm{x} / 1-\mathrm{x}$; the likelihood of successfully/ failure of detecting the rent-seeking is $\mathrm{q} / 1-\mathrm{q}$; the likelihood of the supervisor's decision of rent seeking/ no rent-seeking is $y / 1-y$; the likelihood of the contractor to accept/ refuse the rent-seeking is $\mathrm{z} / 1-\mathrm{z}$.

(4) All the variables are real positive numbers. And $0<\mathrm{x}<1 ; 0<\mathrm{y}<1 ; 0<\mathrm{z}<1 ; 0<\mathrm{q}<1 ; 0<\mathrm{k}<1 ;$ $\mathrm{e}>0 ; \mathrm{d}>0 ; \mathrm{P}>0 ; \mathrm{m}>1 ; \mathrm{n}>1$.

According to rent-seeking theory and evolutionary game theory, the four factors on rent-seeking are obvious to obtain based on practices of construction project, including supervision cost, supervision likelihood, supervision success rate and penalty intensity factor. Similar studies can be seen in previous related researches (Feng et al., 2019; Mei et al., 2017; Shurong \& Miao, 2012). Additionally, complexity and the unprecedented scales of projects make them difficult to manage, the cost often increases with the scale of the project (Yang et al., 2018). Therefore, the project size can be seen as an equally important factor. Specially, project scale (P) refers to the size of the project to be supervised by the supervisor. If the scale of a single project is big, the owners can divide it into several smaller unit projects and hire the same number of supervisors to supervise them separately. So, project scale can be changed in the middle stage of project supervision. The value of project size $(\mathrm{P})$ is a relative value, which is simply calculated according to the area of the supervised project.

\section{Rent-seeking decisions game model of project main participants}

Based on the theory and methodology of evolutionary game, the behavior decisions of the owner, supervisor and contractor involved in the project depend on the payoff of their own behaviors. Therefore, a payoff matrix of the trilateral game is established based on the previous assumptions, as shown in Table 1.

\subsection{The payoff model of each participant}

As a bounded rational participant prefers the strategies whose payoff is better than the others on replicator dynamics, based on the payoff matrix, the payoff models of the owner, supervisor and contractor are constructed separately.

\subsubsection{The payoff model of the owner}

Assuming that the owner's payoff when the supervision strategy is chosen is $\mathrm{E}_{\mathrm{A} 1}$ and the payoff otherwise is $\mathrm{E}_{\mathrm{A} 2}$, $\mathrm{E}_{\mathrm{A} 1}$ and $\mathrm{E}_{\mathrm{A} 2}$ are calculated by Eqns (1) and (2). 
Table 1. The payoff matrix of the trilateral game

\begin{tabular}{|c|c|c|c|c|}
\hline & \multicolumn{2}{|c|}{$\begin{array}{c}\text { Owner }(A) \\
\text { supervises }(\mathrm{x})\end{array}$} & \multirow{2}{*}{$\begin{array}{c}\text { Owner }(A) \\
\text { does not supervise } \\
(1-\mathrm{x})\end{array}$} \\
\hline & & $\operatorname{success}(\mathrm{q})$ & fail $(1-q)$ & \\
\hline \multirow{2}{*}{$\begin{array}{l}\text { Supervisor }(B) \\
\text { seeks rent }(\mathrm{y})\end{array}$} & $\begin{array}{l}\text { Contractor }(C) \text { accepts } \\
\text { rent-seeking }(\mathrm{z})\end{array}$ & $\begin{array}{l}\{\mathrm{V}+(\mathrm{m}+\mathrm{nk}) \mathrm{R}-\mathrm{dP}-\mathrm{eP}, \\
(1-\mathrm{n}) \mathrm{kR}+\mathrm{eP},(1-\mathrm{m}-\mathrm{k}) \mathrm{R}\}\end{array}$ & $\begin{array}{l}\{\mathrm{V}-\mathrm{R}-\mathrm{dP}-\mathrm{eP} \\
\mathrm{eP}+\mathrm{kR},(1-\mathrm{k}) \mathrm{R}\}\end{array}$ & $\begin{array}{l}\{\mathrm{V}-\mathrm{R}-\mathrm{eP}, \\
\mathrm{eP}+\mathrm{kR},(1-\mathrm{k}) \mathrm{R}\}\end{array}$ \\
\hline & $\begin{array}{l}\text { Contractor }(C) \\
\text { refuses rent-seeking } \\
(1-\mathrm{z})\end{array}$ & $\{\mathrm{V}-\mathrm{dP}-\mathrm{eP}, \mathrm{eP}, 0\}$ & $\{\mathrm{V}-\mathrm{dP}-\mathrm{eP}, \mathrm{eP}, 0\}$ & $\{\mathrm{V}-\mathrm{eP}, \mathrm{eP}, 0\}$ \\
\hline \multirow{2}{*}{$\begin{array}{l}\text { Supervisor }(B) \\
\text { does not seek } \\
\text { rent }(1-\mathrm{y})\end{array}$} & $\begin{array}{l}\text { Contractor }(C) \text { accepts } \\
\text { rent-seeking }(\mathrm{z})\end{array}$ & $\{\mathrm{V}-\mathrm{dP}-\mathrm{eP}, \mathrm{eP}, 0\}$ & $\{\mathrm{V}-\mathrm{dP}-\mathrm{eP}, \mathrm{eP}, 0\}$ & $\{\mathrm{V}-\mathrm{eP}, \mathrm{eP}, 0\}$ \\
\hline & $\begin{array}{l}\text { Contractor }(C) \\
\text { refuses rent-seeking } \\
(1-\mathrm{z})\end{array}$ & $\{\mathrm{V}-\mathrm{dP}-\mathrm{eP}, \mathrm{eP}, 0\}$ & $\{\mathrm{V}-\mathrm{dP}-\mathrm{eP}, \mathrm{eP}, 0\}$ & $\{\mathrm{V}-\mathrm{eP}, \mathrm{eP}, 0\}$ \\
\hline
\end{tabular}

Note: In this payoff matrix, three values of each group of data represent the total revenue of the owners, supervisors and contractors respectively under the corresponding strategy selection. For example, the first set of data $\{\mathrm{V}+(\mathrm{m}+\mathrm{nk}) \mathrm{R}-\mathrm{dP}-\mathrm{eP},(1-\mathrm{n}) \mathrm{kR}+\mathrm{eP}$, $(1-\mathrm{m}-\mathrm{k}) \mathrm{R}\}$ means that the owner chooses to supervise and supervises successfully. At the same time, in the case of rent-seeking by both the supervisor and the contractor, the total revenue of the owner is $\mathrm{V}+(\mathrm{m}+\mathrm{nk}) \mathrm{R}-\mathrm{dP}-\mathrm{eP}$, the total revenue of the supervisor is $(1-n) k R+e P$, and the total revenue of the contractor is $(1-m-k) R$. Among them, the total revenue of the owner includes the owner's normal revenue $\mathrm{V}$, the penalty $\mathrm{mR}$ for the contractor after successful supervision and verification, the penalty nkR for the supervisor, the supervision cost $\mathrm{dP}$ and the supervisor's remuneration $\mathrm{eP}$. Similarly, the total revenue of other participants under different strategy combinations can be obtained.

$\mathrm{E}_{\mathrm{A} 1}=\mathrm{yzq}[\mathrm{V}+(\mathrm{m}+\mathrm{nk}) \mathrm{R}-\mathrm{dP}-\mathrm{eP}]+$

$\mathrm{yz}(1-\mathrm{q})(\mathrm{V}-\mathrm{R}-\mathrm{dP}-\mathrm{eP})+$

$y(1-z) q(V-d P-e p)+$

$\mathrm{y}(1-\mathrm{z})(1-\mathrm{q})(\mathrm{V}-\mathrm{dP}-\mathrm{eP})+$

$(1-\mathrm{y}) \mathrm{zq}(\mathrm{V}-\mathrm{dP}-\mathrm{eP})+$

$(1-\mathrm{y}) \mathrm{z}(1-\mathrm{q})(\mathrm{V}-\mathrm{dP}-\mathrm{eP})+$

$(1-\mathrm{y})(1-\mathrm{z}) \mathrm{q}(\mathrm{V}-\mathrm{dP}-\mathrm{eP})+$

$(1-\mathrm{y})(1-\mathrm{z})(1-\mathrm{q})(\mathrm{v}-\mathrm{dP}-\mathrm{eP})$;

$\mathrm{E}_{\mathrm{A} 2}=\mathrm{yz}(\mathrm{V}-\mathrm{R}-\mathrm{ep})+\mathrm{y}(1-\mathrm{z})(\mathrm{V}-\mathrm{eP})+$

$(1-y) z(V-e P)+(1-y)(1-z)(V-e P)$.

The simplification of the two equations above are:

$\mathrm{E}_{\mathrm{A} 1}=\mathrm{V}-\mathrm{dP}-\mathrm{eP}+\mathrm{yzR}[(\mathrm{m}+\mathrm{nk}+1) \mathrm{q}-1] ;$

$\mathrm{E}_{\mathrm{A} 2}=\mathrm{V}-\mathrm{eP}-\mathrm{yzR}$.

\subsubsection{The payoff model of the supervisor}

Assuming that the supervisor's payoff when rent-seeking is chosen is $\mathrm{E}_{\mathrm{B} 1}$ and the payoff otherwise is $\mathrm{E}_{\mathrm{B} 2}, \mathrm{E}_{\mathrm{B} 1}$ and $\mathrm{E}_{\mathrm{B} 2}$ can be calculated by Eqns (5) and (6).

$$
\begin{aligned}
& \mathrm{E}_{\mathrm{B} 1}=\mathrm{xqz}[(1-\mathrm{n}) \mathrm{kR}+\mathrm{eP}]+\mathrm{x}(1-\mathrm{q}) \mathrm{z}(\mathrm{ep}+\mathrm{kR})+ \\
& (1-\mathrm{x}) \mathrm{z}(\mathrm{ep}+\mathrm{kR})+\mathrm{xq}(1-\mathrm{z}) \mathrm{eP}+\mathrm{x}(1-\mathrm{q})(1-\mathrm{z}) \mathrm{eP}+ \\
& (1-\mathrm{x})(1-\mathrm{z}) \mathrm{eP} ; \\
& \mathrm{E}_{\mathrm{B} 2}=[\mathrm{zxq}+\mathrm{zx}(1-\mathrm{q})+\mathrm{z}(1-\mathrm{x})+(1-\mathrm{z}) \mathrm{xq}+ \\
& (1-\mathrm{z}) \mathrm{x}(1-\mathrm{q})+(1-\mathrm{z})(1-\mathrm{x})] \mathrm{eP} .
\end{aligned}
$$

The simplifications of the two equations above are:

$$
\begin{aligned}
& \mathrm{E}_{\mathrm{B} 1}=\mathrm{zkR}(1-\mathrm{nxq})+\mathrm{eP} ; \\
& \mathrm{E}_{\mathrm{B} 2}=\mathrm{eP} .
\end{aligned}
$$

\subsubsection{The payoff model of the contractor}

Assuming that the contractor's payoff of choosing to agree the rent-seeking is $\mathrm{E}_{\mathrm{C} 1}$ and the payoff otherwise is $\mathrm{E}_{\mathrm{C} 2}$, $\mathrm{E}_{\mathrm{C} 1}$ and $\mathrm{E}_{\mathrm{C} 2}$ can be calculated by Eqns (9) and (10).

$$
\begin{aligned}
& \mathrm{E}_{\mathrm{C} 1}=\mathrm{xqy}[(1-\mathrm{m}-\mathrm{k}) \mathrm{R}]+\mathrm{x}(1-\mathrm{q}) \mathrm{y}(1-\mathrm{k}) \mathrm{R}+ \\
& (1-\mathrm{x}) \mathrm{y}(1-\mathrm{k}) \mathrm{R} ; \\
& \mathrm{E}_{\mathrm{C} 2}=0 .
\end{aligned}
$$

The simplifications of the equations are:

$$
\begin{aligned}
& \mathrm{E}_{\mathrm{C} 1}=\mathrm{yR}(1-\mathrm{k}-\mathrm{xqm}) ; \\
& \mathrm{E}_{\mathrm{C} 2}=0 .
\end{aligned}
$$

\subsection{The replicated dynamic equation and the stability of the evolutionary game}

In order to analysis the evolutionary game process among the owner, supervisor and contractor, the replicated dynamic equations based on the evolutionary game theory are proposed, as shown in Eqns (13)-(15).

$$
\begin{aligned}
& \frac{\mathrm{dx}}{\mathrm{dt}}=\mathrm{x}\left(\mathrm{E}_{\mathrm{A} 1}-\overline{\mathrm{E}}_{\mathrm{A}}\right)=\mathrm{x}\left\{\mathrm{E}_{\mathrm{A} 1}-\left[\mathrm{xE}_{\mathrm{A} 1}+(1-\mathrm{x}) \mathrm{E}_{\mathrm{A} 2}\right]\right\}= \\
& \mathrm{x}(1-\mathrm{x})\left(\mathrm{E}_{\mathrm{A} 1}-\mathrm{E}_{\mathrm{A} 2}\right) ; \\
& \frac{\mathrm{dy}}{\mathrm{dt}}=\mathrm{y}\left(\mathrm{E}_{\mathrm{B} 1}-\overline{\mathrm{E}}_{\mathrm{B}}\right)=\mathrm{y}\left\{\mathrm{E}_{\mathrm{B} 1}-\left[\mathrm{yE}_{\mathrm{B} 1}+(1-\mathrm{y}) \mathrm{E}_{\mathrm{B} 2}\right]\right\}= \\
& \mathrm{y}(1-\mathrm{y})\left(\mathrm{E}_{\mathrm{B} 1}-\mathrm{E}_{\mathrm{B} 2}\right) ; \\
& \frac{\mathrm{dz}}{\mathrm{dt}}=\mathrm{z}\left(\mathrm{E}_{\mathrm{C} 1}-\overline{\mathrm{E}}_{\mathrm{C}}\right)=\mathrm{z}\left\{\mathrm{E}_{\mathrm{C} 1}-\left[\mathrm{zE}_{\mathrm{C} 1}+(1-\mathrm{z}) \mathrm{E}_{\mathrm{C} 2}\right]\right\}= \\
& \mathrm{z}(1-\mathrm{z})\left(\mathrm{E}_{\mathrm{C} 1}-\mathrm{E}_{\mathrm{C} 2}\right) .
\end{aligned}
$$


Equations (3), (4), (7), (8), (11) and (12) are substituted into Eqn (13) to Eqn (15) above, and the following equations can be obtained.

$$
\begin{aligned}
& \frac{d x}{d t}=x(1-x)[y z q R(m+n k+1)-d P] \\
& \frac{d y}{d t}=y(1-y) z k R(1-n x q) ; \\
& \frac{d z}{d t}=z(1-z)(1-k-x q m) y R .
\end{aligned}
$$

The evolutionary stability of the strategies of owner A, supervisor $\mathrm{B}$ and contractor $\mathrm{C}$ is analyzed as follows.

\subsubsection{Evolutionary stable analysis of owner A}

Equation (16) is the replicated dynamic equation of owner $A: \frac{d x}{d t}=x(1-x)[y z q R(m+n k+1)-d P]$, let $F(x)=$ $\frac{\mathrm{dx}}{\mathrm{dt}}=\mathrm{x}(1-\mathrm{x})[\mathrm{yzqR}(\mathrm{m}+\mathrm{nk}+1)-\mathrm{dP}]$. The specific analysis of the strategic stability of the owner is as follows:

(1) When $y z=\frac{d P}{q R(m+n k+1)}$, then $F(x) \equiv 0$, and any $\mathrm{x}$ is a stable point.

(2) When $y z \neq \frac{d P}{q R(m+n k+1)}$, let $F(x)=0$, obtain that $\mathrm{x}=0$ and $\mathrm{x}=1$ are two stable states of the replicated dynamics. Then the neighborhood stability of the stable state is discussed, that is, the equilibrium state with robustness for small deviation disturbance is discussed. According to nature of evolutionary game stable strategy and the stable theorem of differential equation, when a stable state must be robust to small disturbances, it is the evolutionary stable strategy (ESS) of game. The derivative $\mathrm{F}^{\prime}\left(\mathrm{x}^{*}\right)$ of $\mathrm{F}(\mathrm{x})$ must be less than zero at the stable state $\mathrm{x}^{*}$, that is, when $\frac{\mathrm{dF}\left(\mathrm{x}^{*}\right)}{\mathrm{dx}}<0, \mathrm{x}^{*}$ is the evolutionary stable strategy (ESS).

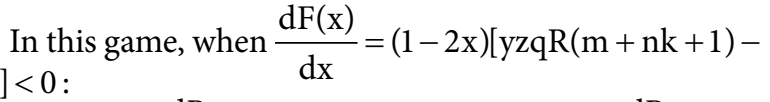
$\mathrm{dP}]<0$ :

1) If $\frac{\mathrm{dP}}{\mathrm{qR}(\mathrm{m}+\mathrm{nk}+1)}>1$, then $\mathrm{yz}<1<\frac{\mathrm{dP}}{\mathrm{qR}(\mathrm{m}+\mathrm{nk}+1)}$, and $\mathrm{x}=0$ is an evolutionary stable strategy (ESS).

2) If $\frac{\mathrm{dP}}{\mathrm{qR}(\mathrm{m}+\mathrm{nk}+1)}<1$, it is divided into two situations:

when $\frac{\mathrm{dP}}{\mathrm{qR}(\mathrm{m}+\mathrm{nk}+1)}<\mathrm{yz}<1$, then $\mathrm{x}=1$ is an evolutionary stable strategy (ESS);

when $\mathrm{yz}<\frac{\mathrm{dP}}{\mathrm{qR}(\mathrm{m}+\mathrm{nk}+1)}<1$, then $\mathrm{x}=0$ is an evolutionary stable strategy (ESS).

\subsubsection{Evolutionary stable analysis of supervisor $B$}

Equation (17) is the replicated dynamic equation of supervisor $B$ : $\frac{d y}{d t}=y(1-y) z k R(1-n x q)$, let $F(y)=\frac{d y}{d t}=y(1-$
y)zkR( $1-\mathrm{nxq})$. The specific analysis of the strategic stability of the supervisor is as follows:

(1) When $\mathrm{x}=\frac{1}{\mathrm{nq}}$, then $\mathrm{F}(\mathrm{y}) \equiv 0$, and any $\mathrm{y}$ is a stable point.

(2) When $x \neq \frac{1}{n q}$, let $F(y)=0$, obtain that $y=0$ and $y=1$ are two stable states of the replicated dynamics. According to the nature of evolutionary game stable strategy and the stable theorem of differential equation, when a stable state must be robust to small disturbances, it is the evolutionary stable strategy (ESS) of game. The derivative $\mathrm{F}^{\prime}\left(\mathrm{y}^{*}\right)$ of $\mathrm{F}(\mathrm{y})$ must be less than zero at the stable state $y^{*}$, that is, when $\frac{d F\left(y^{*}\right)}{d y}<0, y^{*}$ is the evolutionary stable strategy (ESS).

In this game, when $\frac{\mathrm{dF}(\mathrm{y})}{\mathrm{dy}}=(1-2 \mathrm{y}) \mathrm{zkR}(1-\mathrm{nxq})<0$ : 1) If $\frac{1}{n q}>1$, then $x<1<\frac{1}{n q}$, at this time $1-n x q>$ 0 , and $y=1$ is an evolutionary stable strategy (ESS).

2) If $\frac{1}{n q}<1$, it is divided into two situations: when $\frac{1}{\mathrm{nq}}<\mathrm{x}<1$, then $1-\mathrm{nxq}<0$, and $\mathrm{y}=0$ is an evolutionary stable strategy (ESS);

when $\mathrm{x}<\frac{1}{\mathrm{nq}}<1$, then $1-\mathrm{nxq}>0$, and $\mathrm{y}=1$ is an evolutionary stable strategy (ESS).

\subsubsection{Evolutionary stable analysis of contractor $\mathrm{C}$}

Equation (18) is the replicated dynamic equation of contractor $\mathrm{C}: \frac{\mathrm{dz}}{\mathrm{dt}}=\mathrm{z}(1-\mathrm{z})(1-\mathrm{k}-\mathrm{xqm}) \mathrm{yR}$, let $\mathrm{F}(\mathrm{z})=$ $\frac{\mathrm{dz}}{\mathrm{dt}}=\mathrm{z}(1-\mathrm{z})(1-\mathrm{k}-\mathrm{xqm}) \mathrm{yR}$. The specific analysis of the strategic stability of the contractor is as follows:

(1) When $\mathrm{x}=\frac{1-\mathrm{k}}{\mathrm{qm}}$, then $\mathrm{F}(\mathrm{z}) \equiv 0$, and any $\mathrm{z}$ is a stable point.

(2) When $x \neq \frac{1-k}{q m}$, let $F(z)=0$, obtain that $z=0$ and $\mathrm{z}=1$ are two stable states of the replicated dynamics.

According to the nature of evolutionary game stable strategy and the stable theorem of differential equation, when a stable state must be robust to small disturbances, it is the evolutionary stable strategy (ESS) of game. The derivative $\mathrm{F}^{\prime}\left(\mathrm{z}^{*}\right)$ of $\mathrm{F}(\mathrm{z})$ must be less than zero at the stable state $z^{*}$, that is, when $\frac{\mathrm{dF}\left(\mathrm{z}^{*}\right)}{\mathrm{dz}}<0, \mathrm{z}^{*}$ is the evolutionary stable strategy (ESS).

In this game, when $\frac{\mathrm{dF}(\mathrm{z})}{\mathrm{dz}}=(1-2 \mathrm{z})(1-\mathrm{k}-\mathrm{xqm}) \mathrm{yR}<0$ : 1) If $\frac{1-\mathrm{k}}{\mathrm{qm}}>1$, then $\mathrm{x}<1<\frac{1-\mathrm{k}}{\mathrm{qm}}$, at this time $1-\mathrm{k}-$ $\mathrm{xqm}>0$, and $\mathrm{z}=1$ is an evolutionary stable strategy (ESS).

2) If $\frac{1-\mathrm{k}}{\mathrm{qm}}<1$, it is divided into two situations: 
when $\frac{1-\mathrm{k}}{\mathrm{qm}}<\mathrm{x}<1$, then $1-\mathrm{k}-\mathrm{xqm}<0$, and $\mathrm{z}=$ 0 is an evolutionary stable strategy (ESS);

when $\mathrm{x}<\frac{1-\mathrm{k}}{\mathrm{qm}}<1$, then $1-\mathrm{k}-\mathrm{xqm}>0$, and $\mathrm{z}=$ 1 is an evolutionary stable strategy (ESS).

\section{Simulation and discussion based on system dynamics}

In order to simulate the game process of the three participates, based on the Eqns (16) to (18), the system dynamic model is established via Vensim software. The system flow diagram is shown in Figure 2. In this simulation, according to the previous evolutionary game assumptions, the owner supervision cost is expressed as $\mathrm{d} \times \mathrm{P}$. The supervisor gets a bribe of $\mathrm{k} \times \mathrm{R}$ from the contractors. The penalty intensity on the contractor is expressed as $\mathrm{m} \times \mathrm{R}$. The penalty intensity on the supervisor is expressed as $\mathrm{n} \times \mathrm{k} \times \mathrm{R}$.

Based on the established game utility matrix and replicated dynamic equation of three participants in engineering construction, the system dynamics model is constructed for simulation analysis. In order to predict and compare dynamic simulation clearly and intuitively, this paper takes GS project as an example for simulation calculation. For the generality of simulation, based on evolutionary stable analysis, the parameters meet the conditions:

$$
\frac{\mathrm{dP}}{\mathrm{qR}(\mathrm{m}+\mathrm{nk}+1)}<1, \frac{1}{\mathrm{nq}}<1, \frac{1-\mathrm{k}}{\mathrm{qm}}<1 .
$$

In this project case, the initial scale of the project is 5 , the owner's avenue $(\mathrm{V})$ is $100,000 \mathrm{CNY}$ if the project is delivered on schedule, the supervision fee of the supervi- sor paid by the owner is $15,000 \mathrm{CNY}$ (e is 0.3 ) and the addition supervision cost of the owner is $10,000 \mathrm{CNY}$ (d is 0.2). If the rent-seeking happens, the contractor can get an illegal revenue (R) of $8,000 \mathrm{CNY}$ and the bribe given to the supervisor by the contractor is $3,200 \mathrm{CNY}$ ( $\mathrm{k}$ is 0.4 ). The likelihood of the owner's successful detection of the rent-seeking is 0.7 . When detected, the owner will claim 2 times the supervisor's illegal revenue $(\mathrm{n}=2)$ and 1.5 times the contractor's illegal revenue $(m=1.5)$. The specific parameters are shown in Table 2.

Table 2. The parameters of the three participants gaming of the case project

\begin{tabular}{|c|c|c|c|}
\hline Parameters & Value & Parameters & Value \\
\hline $\mathrm{V}$ & 100,000 & $\mathrm{R}$ & 8,000 \\
\hline $\mathrm{P}$ & 5 & $\mathrm{k}$ & 0.4 \\
\hline $\mathrm{q}$ & 0.7 & $\mathrm{n}$ & 2 \\
\hline $\mathrm{d}$ & 0.2 & $\mathrm{~m}$ & 1.5 \\
\hline $\mathrm{e}$ & 0.3 & & \\
\hline
\end{tabular}

\subsection{The evolutionary stability of the game model}

The first step of the evolutionary game analysis is to check its evolutionary stability. By setting up four groups of different initial values of $x, y$, and $z$ to simulate: $(x=0.3, y=$ $0.2, \mathrm{z}=0.2),(\mathrm{x}=0.5, \mathrm{y}=0.2, \mathrm{z}=0.2),(\mathrm{x}=0.7, \mathrm{y}=0.2$, $\mathrm{z}=0.2),(\mathrm{x}=0.5, \mathrm{y}=0.5, \mathrm{z}=0.5)$, the simulation results corresponding to four groups of initial values can be obtained, as shown in Figure 3.

According to Figure 3, although the likelihoods of the three participants' behavior decisions are different, the evolution results of the $\mathrm{x}, \mathrm{y}$ and $\mathrm{z}$ are all equal to 1, namely

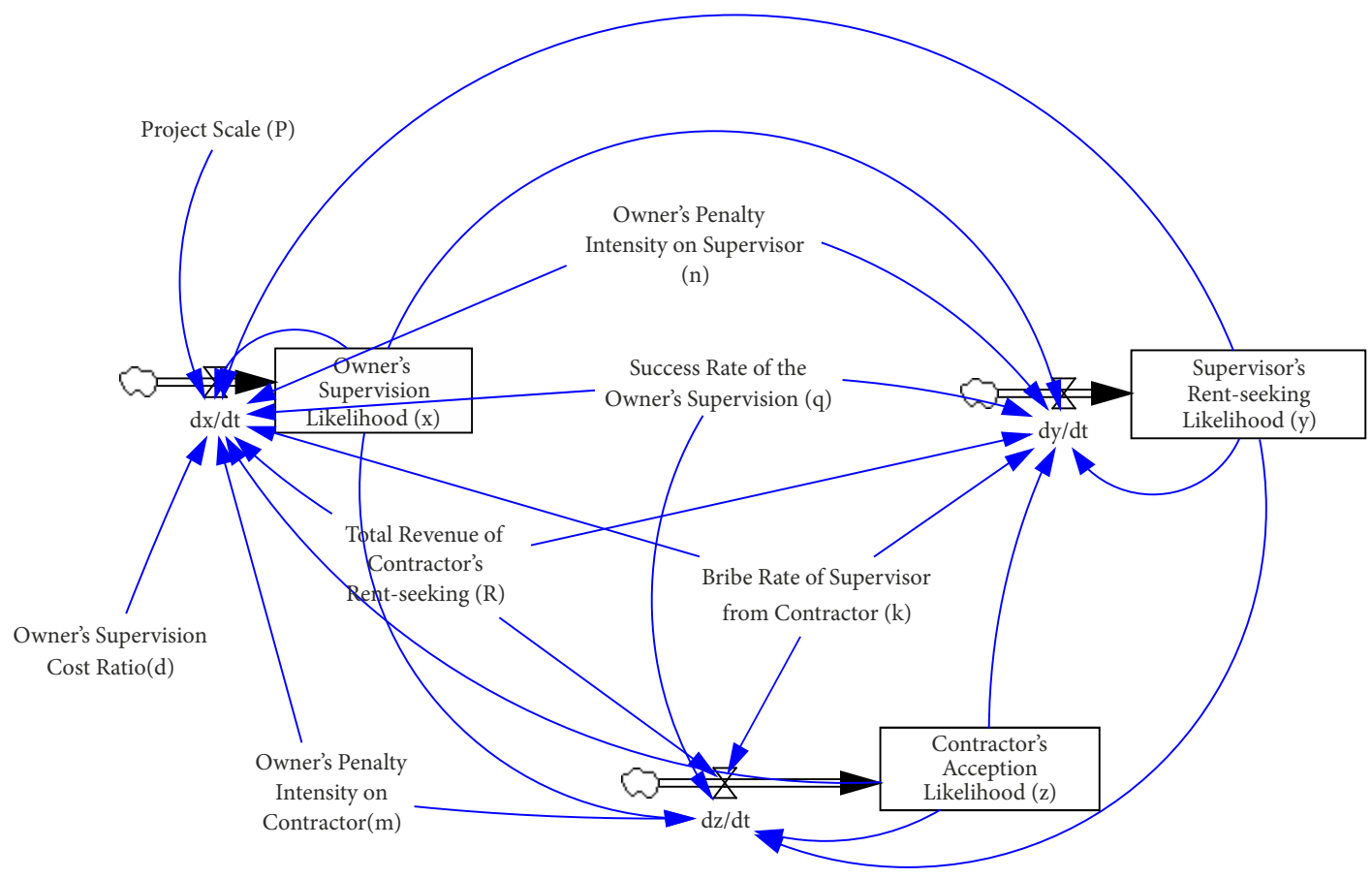

Figure 2. The system flow diagram of the three participants gaming 
the evolution stable point is $(\mathrm{x}=1, \mathrm{y}=1, \mathrm{z}=1)$, indicating that the behavioral strategies of the owner, supervisor and contractor are stable in the states of supervising, seeking rent and accepting rent-seeking. The reasons can be explained as: (1) No matter how likely the owner choose to supervise rent-seeking at first, the supervisor and the contractor will definitely participate in a rent-seeking conspiracy for more benefit. That is because the project, which has a large investment, numerous participants, long construction period and intricate project objectives including quality, schedule, cost, health, safety and environment (HSE), is in a dynamic social-economic environment and difficult to be thoroughly supervised by the owner so that the supervisor and the contractor tend to participate in rent-seeking. (2) No matter what the initial likelihood of the supervisor and contractor choosing to rent-seeking is, the owner will eventually choose to hire $S$ to supervise the
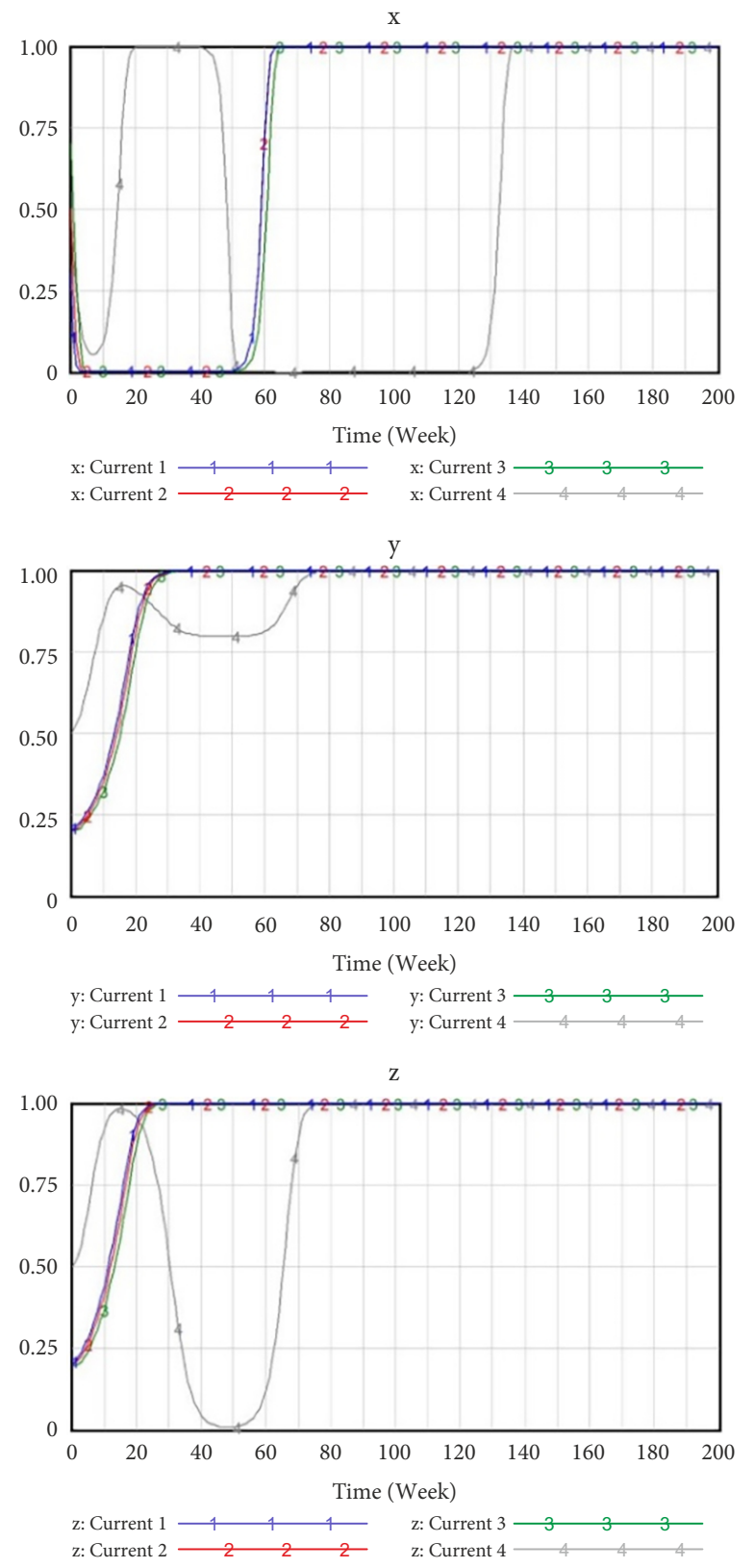

Figure 3. The simulation results of the four initial values behaviors of the supervisor and contractor. As the owners know that the supervisors and the contractors are likely to choose the illegal but more beneficial strategy(rentseeking), supervising them is a preferable strategy.

\subsection{The impact of project scale on the participants' behaviors}

In this simulation, in order to analyze the impact of the change of project scale $(\mathrm{P})$ on the participants' behaviors, the project scale increases from $\mathrm{P} 1(4.5)$ to $\mathrm{P} 2(4.8), \mathrm{P} 3(5.1)$ and finally to $P 4(5.4)$ sequentially while keeping the $x, y$ and $\mathrm{z}$ unchanged $(\mathrm{x}=0.5, \mathrm{y}=0.2, \mathrm{z}=0.2)$. Here, project scale $(\mathrm{P})$ refers to the size of the project to be supervised by the supervisor. If the scale of a single project is big, the owners should divide it into several smaller unit projects and hire a supervisor to supervise them each. The simulation results are shown in Figure 4.
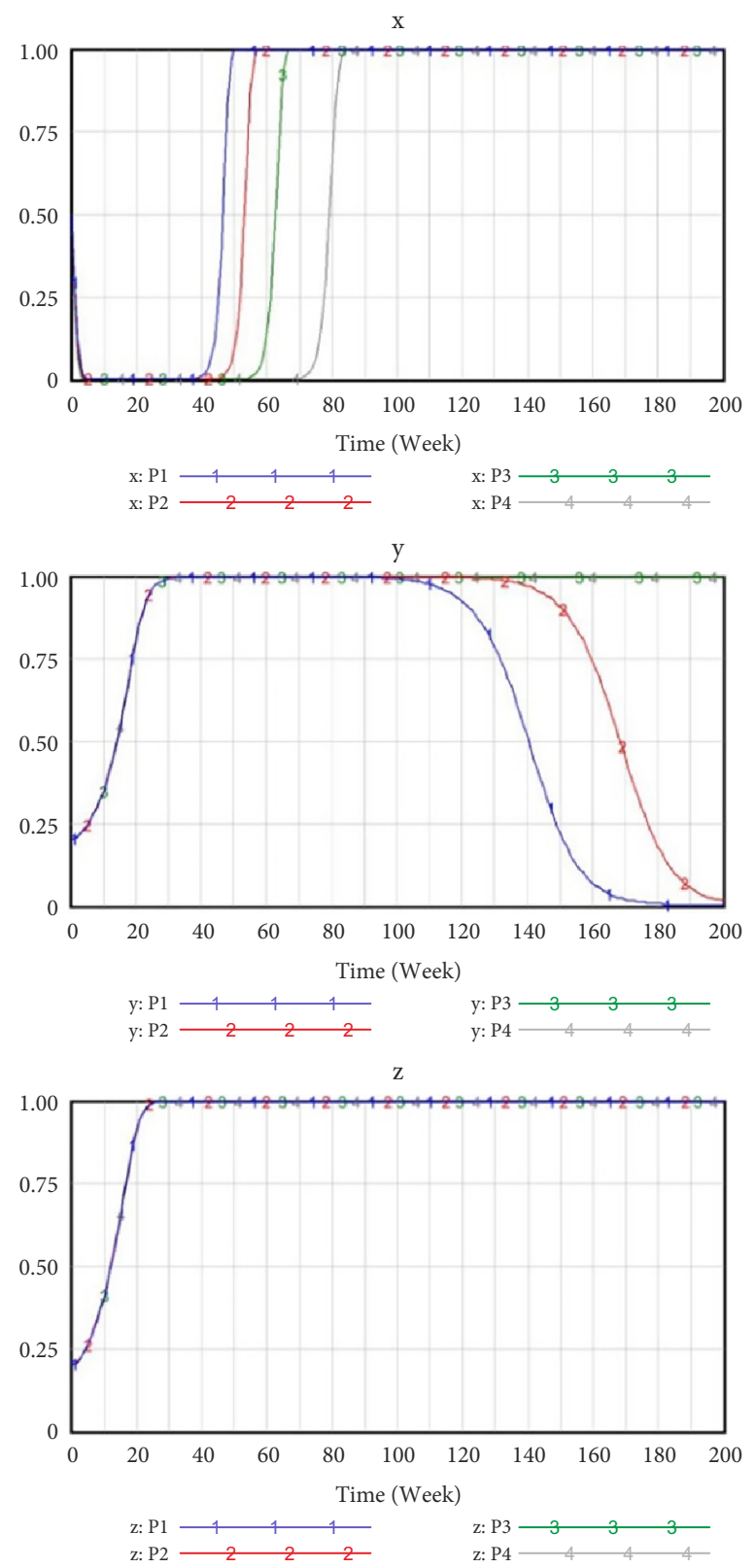

Figure 4. The simulation results under project scale P1, P2, P3 and P4 
According to Figure 4, the change of project scale $\mathrm{P}$ has different effects on the behaviors and decisions of the owner, the supervisor, and the contractor. There are various impacts of project scale on the behavioral decisions of the owner, supervisor and contractor: (1) For the owner, with the increase of the project scale, the time to enter the stable state of supervision is gradually delayed. This phenomenon can be explained that the complexity, invest and schedule increase with the project scale. Therefore, the owner must spend more time on other project issues before supervising the supervisor and contractor. In addition, the supervision cost also increases with the project scale. (2) For the supervisor, as the project scale increases, his behavior shifts from non rent-seeking to rent-seeking. This is because the larger the project scale is, the more difficult it is to detect the rent-seeking of the supervisor. (3) For the contractor, he will always choose to accept the rent-seeking regardless of the project scale. One possible reason is that the irresistible temptation of huge illegal return can drive the contractor to trade the overall project performance for his own interests.

\subsection{The impact of the owner's supervision likelihood on the participants' behaviors}

In this simulation, in order to analyze the impact of the change of owner's supervision likelihood on the participants' behaviors, the likelihood of the owner's supervision changes from $\mathrm{x} 1(0.5)$ to $\mathrm{x} 2(0.7), \mathrm{x} 3(0.8)$, and $\mathrm{x} 4(0.9)$ sequentially while keeping the $y$ and $z$ unchanged $(y=0.5$, $z=0.5$ ). The simulation results are shown in Figure 5.
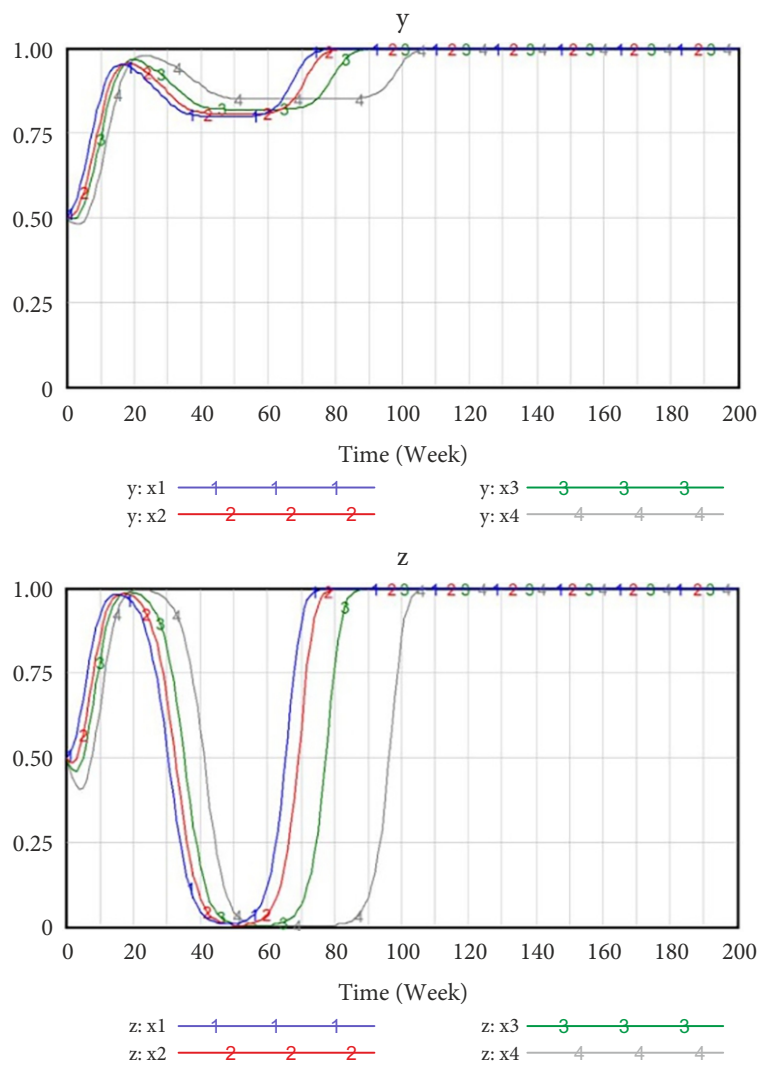

Figure 5. The simulation results of the owner's supervision likelihood x1, x2, x3 and x4
According to Figure 5, it is obvious that the increase of the likelihood of the owner's supervision can postpone the rent-seeking decisions of the supervisor and contractor. This phenomenon indicates that if the owner has more tendency of supervision, although it cannot totally prevent the rent-seeking, it can delay its occurrence. So, more time can be provided to make the project be implemented according to plan. The restriction and warning of the improvement of owner's supervision probability can restrain the illegal and unreasonable profit-seeking behavior of participants to a certain extent.

\subsection{The impact of the success rate of the owner's supervision on the participants' behaviors}

In this simulation, in order to analyze the impact of the success rate of the owner's supervision on the participants' behaviors, the success rate of the owner's supervision changes from $\mathrm{q} 1(0.3)$ to $\mathrm{q} 2(0.5)$, and $\mathrm{q} 3(0.7)$ sequentially while keeping the $\mathrm{x}, \mathrm{y}$ and $\mathrm{z}$ fixed $(\mathrm{x}=0.5, \mathrm{y}=0.2, \mathrm{z}=0.2)$. The simulation results are shown in Figure 6.

According to Figure 6, the impacts of the success rate of the owner's supervision on the behaviors of the owner, supervisor and contractor are different from one another: (1) The impact on owners is reflected in two aspects. First, as the success rate increases, the owner's stable strategy changes from "not supervise" to "supervise". Second, the stable point of the owner's supervision comes earlier with the increase of the success rate. Therefore, when employing professional institutions to supervise the supervisor and contractor, the owner should choose institutions with strong professional knowledge and good reputation to improve the success rate of supervision. (2) The impact on the supervisor is as follows: With the increase of the success rate, the supervisor is less likely to seek rent and, once the rate reaches a certain value, he will give up rentseeking. (3) The impact on the contractor is insignificant, indicating that he will choose to accept the rent-seeking regardless of the success rate of the owner's supervision.

\subsection{The impact of the owner's supervision cost on the participants' behaviors}

From the previous assumptions, the owner supervision cost is expressed as dP. When the project scale (P) is fixed, the supervision cost is directly proportional to $\mathrm{d}$, so this study analyzes the impact of $d$ on the participants' behaviors. In this simulation, in order to analyze the impact of the owner's supervision cost, the supervision cost ratio changes from $\mathrm{d} 1(0.18)$ to $\mathrm{d} 2(0.19)$, and $\mathrm{d} 3(0.20)$ sequentially while the $\mathrm{x}, \mathrm{y}$ and $\mathrm{z}$ remain unchanged $(\mathrm{x}=0.5, \mathrm{y}=$ $0.2, z=0.2$ ). The simulation results are shown in Figure 7.

Based on Figure 7, the impacts of the owner's supervision cost on the behaviors of the owner, supervisor and contractor are different from one another: (1) For the owner, as the supervision cost ratio(d) increases, the owner needs to invest more staff, funds, and time on his supervision, which leads to postpone choosing supervision. 
$\mathrm{X}$

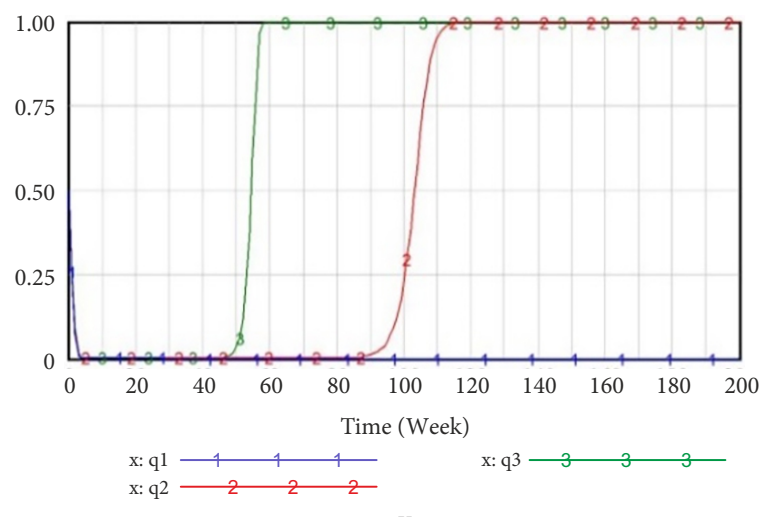

y
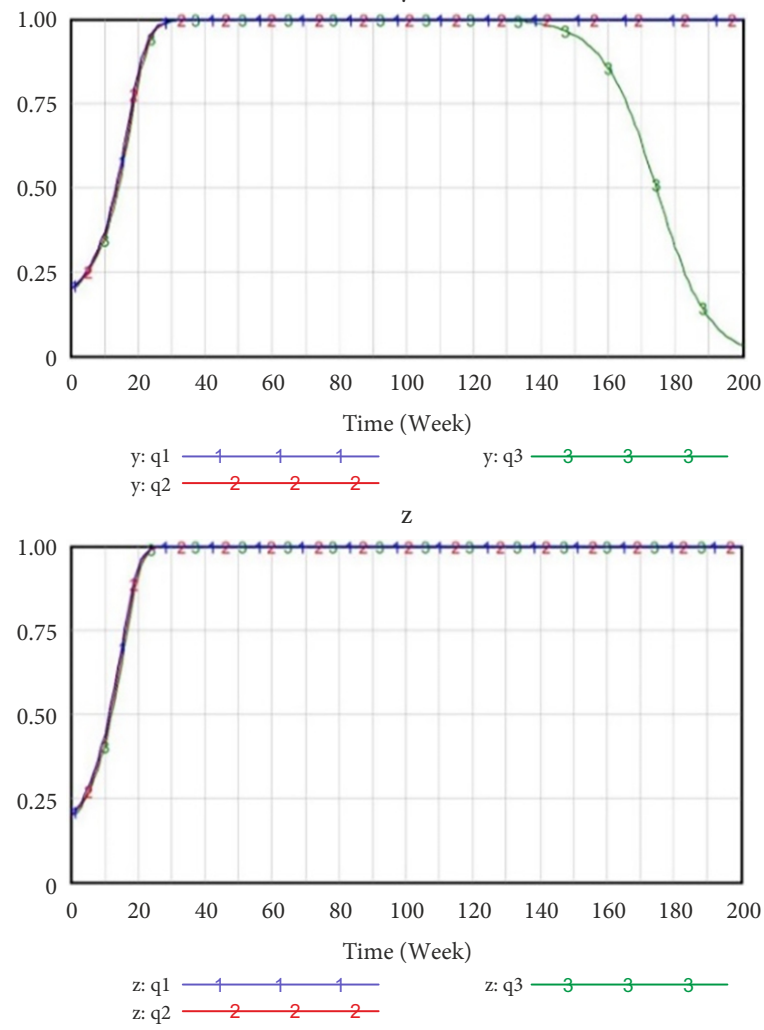

Figure 6. The simulation results of the success rate of the owner's supervision of $\mathrm{q} 1, \mathrm{q} 2$ and $\mathrm{q} 3$

(2) For the supervisor, as the owner's supervision cost increases, the behavior of the supervisor will shift from non rent-seeking to rent-seeking. That is to say, the increase of owner's supervision cost will encourage supervisor's rent-seeking decisions. The result shows that under the condition that the supervision likelihood and success rate remain unchanged, the owner increases the supervision cost and invests more staff and funds simply, which cannot effectively reduce the rent-seeking. On the contrary, it is easier for the supervisor to find that he is being supervised and take tricks to avoid being caught rent-seeking. (3) For the contractor, there is no impact of the supervision cost on him because he is so lured by the huge illegal revenue that he will take the risk of rent-seeking.
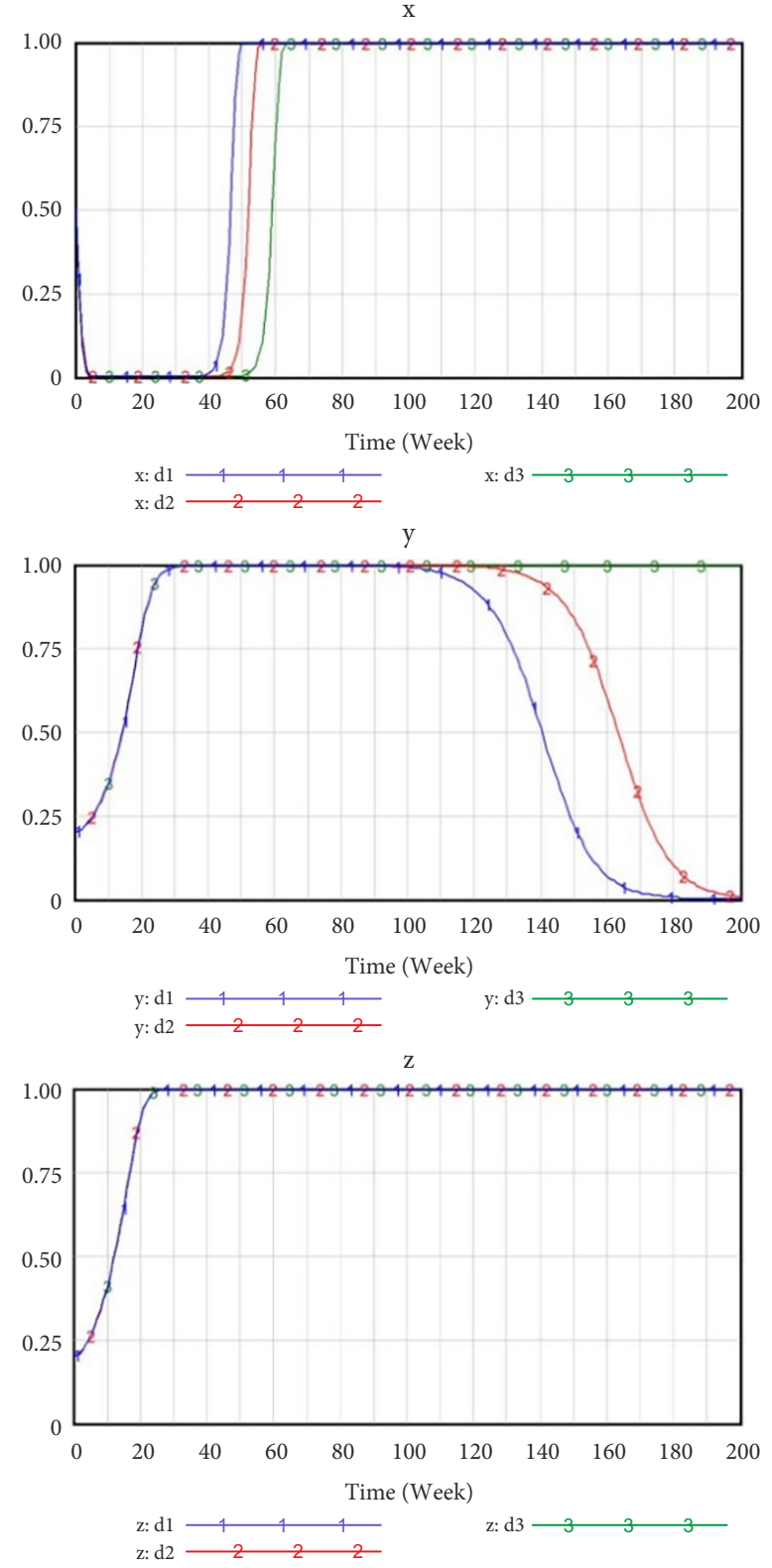

Figure 7. The simulation results of the owner's supervision cost of $\mathrm{d} 1, \mathrm{~d} 2$ and $\mathrm{d} 3$

\subsection{The impact of the owner's penalty intensity on the participants' behaviors}

As the owner will penalize the supervisor and contractor when rent-seeking is detected, the impact of the owner's penalty intensity on the supervisor and contractor is discussed separately. In both situations, the $\mathrm{x}, \mathrm{y}$, and $\mathrm{z}$ remain unchanged, namely $\mathrm{x}=0.5, \mathrm{y}=0.2$, and $\mathrm{z}=0.2$.

\subsubsection{The impact of the owner's penalty intensity on the supervisor's behaviors}

In the situation of the impact of the owner's penalty intensity on the supervisor's behaviors, the penalty intensity coefficient $(\mathrm{n})$ of the supervisor changes from $\mathrm{n} 1(1.8)$ to $\mathrm{n} 2(2.2)$, and $\mathrm{n} 3(2.5)$ sequentially. The simulation results are shown in Figure 8. 


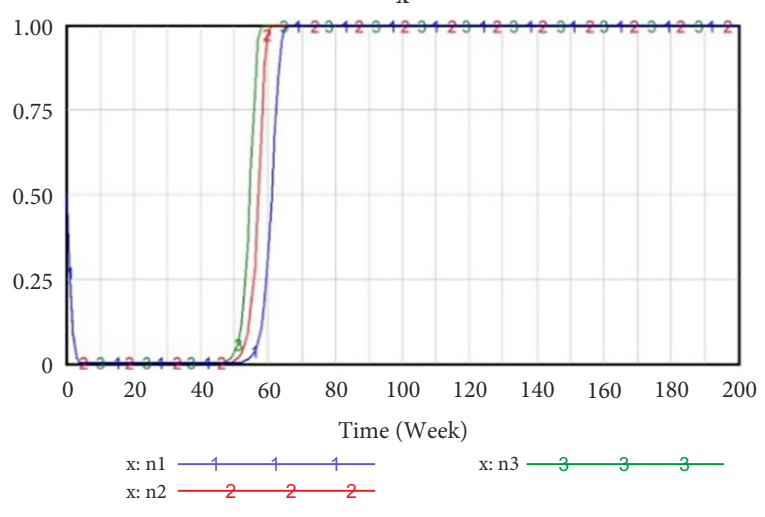

$\mathrm{y}$

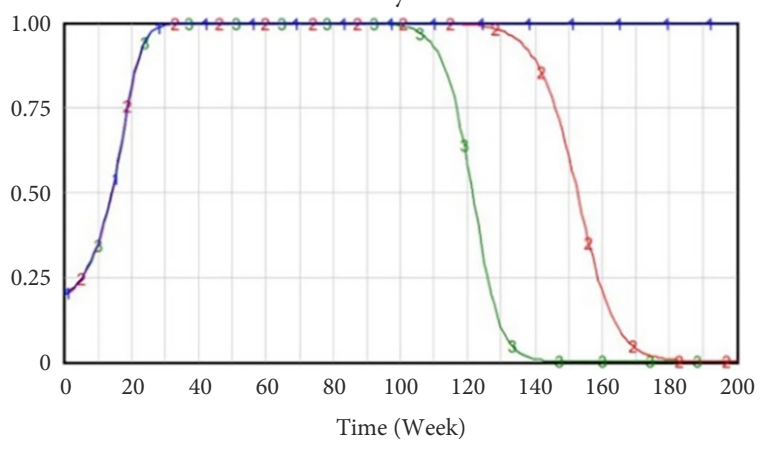

$y: n 1 \frac{1}{212}$

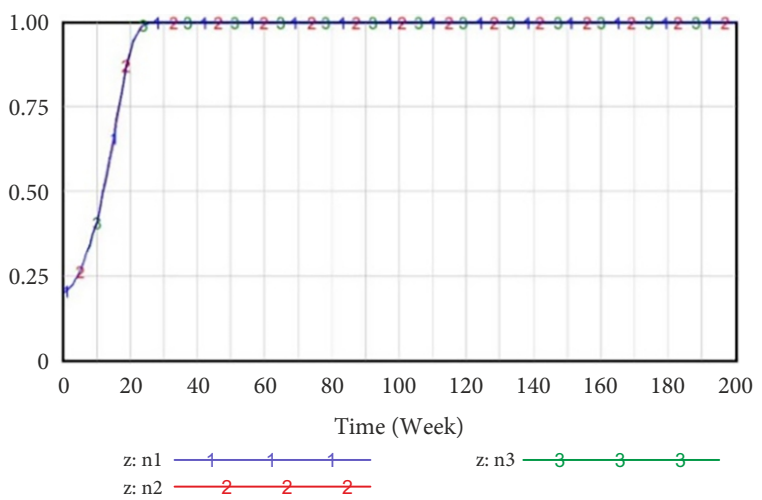

Figure 8 . The simulation results of the owner's penalty intensity on supervisor of $\mathrm{n} 1, \mathrm{n} 2$ and $\mathrm{n} 3$

\subsubsection{The impact of the owner's penalty} intensity on the contractor's behaviors

In the situation of the impact of the owner's penalty intensity on the contractor's behaviors, the penalty intensity coefficient $(\mathrm{m})$ of the contractor changes from $\mathrm{m} 1(1.3)$ to $\mathrm{m} 2$ (1.5) and $\mathrm{m} 3(1.7)$ sequentially. The simulation results are shown in Figure 9.

According to Figure 8 and Figure 9, the change of penalty intensity has a significant impact on the participants' behaviors, especially on the supervisor's behaviors. That is: (1) For the owner, his supervision stability comes earlier as the penalty intensity rises, that is because the owner's motivation of supervision rises with the penalty intensity and thus, he tends to supervise earlier. In other words, with the increase of penalty intensity, owners have more incentive to choose supervision strategy and will

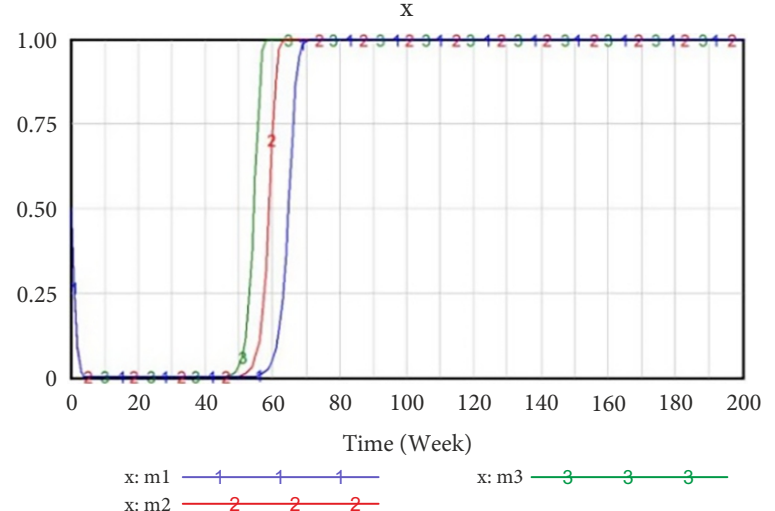

$\mathrm{y}$

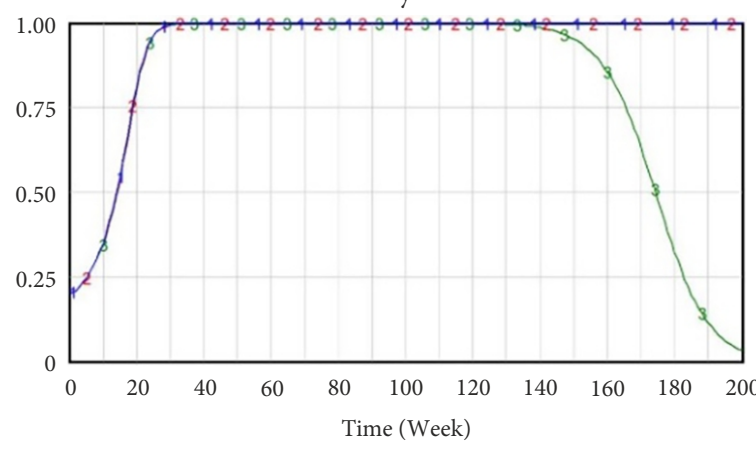

$y: m 1 \frac{1}{2}$\begin{tabular}{lll}
1 & 1 \\
\cline { 1 - 1 } & 2 & 2
\end{tabular}

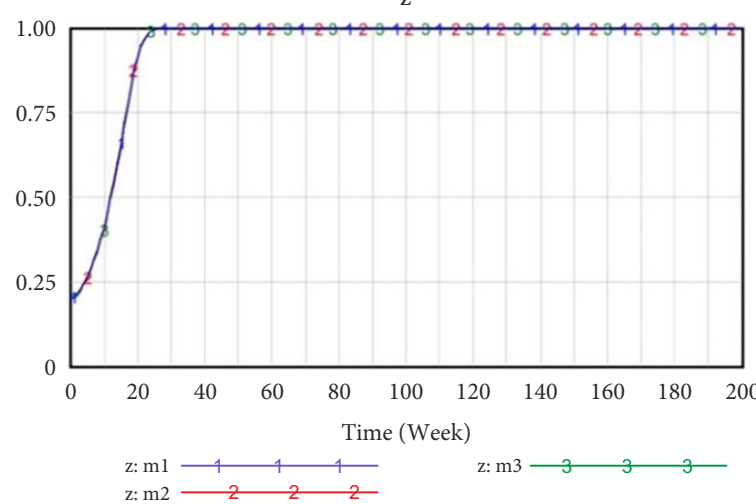

Figure 9. The simulation results of the owner's penalty intensity on contractor of $\mathrm{m} 1, \mathrm{~m} 2$ and $\mathrm{m} 3$

adopt supervision measures earlier. (2) For the supervisor, with the increase of the penalty intensity, the supervisor is forced to alter his strategy from rent-seeking to non rent-seeking, and the higher the penalty intensity is, the earlier the supervisor's stability of non rent-seeking comes. It indicates an obvious deterrent effect on the supervisor of the penalty intensity. (3) For the contractor, the impact of the owner's penalty intensity on him is less significant because the temptation for an additional profit can drive him to take a risk to pursue it.

\section{Conclusions and management implications}

Based on the analysis in the previous chapters, some conclusions can be drawn as follows:

1. During the gaming process of the three project participants, the participants' behaviors of the owner, 
the supervisor and the contractor affect and restrict each other with different extents. In addition, their behavior strategies are also affected by other factors including project scale, supervision cost and supervision success rate. The participants' rent-seeking, which is non-productive, can lead to unfair competition, resource unreasonably distribution and disharmony of the mutual-value-realization among the stakeholders. The final performance of project construction management is determined by the gaming of participants in engineering construction.

2. For the owner, the increase of supervision success rate and penalty intensity can advance his earlier supervision, while the increase of project scale and supervision cost will delay it. It is noteworthy that simply increasing the supervision input without raising the success rate cannot reduce the rent-seeking. On the contrary, such measures may alert the supervisor and contractor and make them use tricks to easier escape from being supervised.

3. For the supervisor, the increase of project scale and the increase of owner's supervision cost can also increase his tendency of rent-seeking, while the increase of supervision probability can delay rentseeking decisions. On the contrary, the increase of supervision success rate and the increase of penalty intensity can prevent rent-seeking, and the further increase of the penalty intensity will promote them to refuse the rent-seeking strategy.

4. For the contractor, the factors such as the temptation of huge interest, belief of good fortune and more consideration of the economical goals can drive him to choose to accept the rent-seeking in any situation. However, the increase of likelihood of the owner's supervision can delay contractor's rent-seeking decisions, while the changes of project scale, supervision success rate, supervision cost and penalty intensity have very limited impact on contractor's rent-seeking decisions.

Based on the evolutionary game and system dynamics simulation analysis above, from the perspective of project owners, some management suggestions to normalize the behavior of participants are put forward as follows:

- First, for a single construction project with a large project scale, it can be appropriately divided into several smaller unit projects for supervision respectively, and the same number supervisors can be hired to supervise these unit projects respectively.

- Second, the owners can properly increase the frequency of supervision to increase the supervision likelihood, which can effectively delay the rent-seeking decisions of the supervisors and contractors.

- Third, the owners should pay attention to the improvement of the success rate of supervision, so professional supervisory entities should be hired as the agents of the owners to supervise the supervisor and the contractor instead of excessively increasing the input of supervision personnel and materials for the supervision. Blind investment cannot effectively prevent rent-seeking decisions of the supervisors and contractors.

- Finally, increasing the penalty intensity on the supervisor and the contractor has a significant deterrent effect on the supervisor and can effectively curb the rent-seeking of the supervisor, but this strategy has a very limited impact on contractors. Therefore, it is advisable that the owners' management and selection of contractors at the tendering-bidding stage should be straightened to award the bid to the contractor with high skill and good reputation level. Only in this way the contractors' rent-seeking behavior can be prevented at the very beginning. In this way, the owner can avoid the occurrence of rent - seeking behavior of the contractor from the beginning of the project.

A new approach, combining the system dynamics method with evolutionary game theory, is used to analyse and simulate the impact of rent-seeking decisions among main participants in this study, and furthermore some management suggestions are proposed to prevent rentseeking based on the analysis. This research can help the project owners to prevent rent-seeking of the supervisors and the contractors to improve the performances of the projects. However, this study has the following limitations or future directions for the subsequent research: First, only the owners, supervisors and contractors who play a key role are considered, while other participants such as designers and suppliers are ignored. More participants will be considered in the following research; Second, this study is carried out under the traditional DBB model. The next step is to study the impacts of other partnering models of projects, such as EPC, BOT et al. and to further study the differences of rent-seeking under different modes; Third, only internal factors are considered, and external environmental factors can be studied to extend the studies on rent-seeking in construction.

\section{Acknowledgements}

Professor Huatao Peng from School of Management, Wuhan University of technology, gave his valuable suggestions on this research. The authors would like to express their gratitude to him.

\section{Funding}

The authors are grateful for the support of Hubei University of Technology Research Startup Fund.

\section{Author contributions}

Qiankun Wang conceived the study and supervised the whole research process. Weiwei Zuo was responsible for evolutionary game model and simulation with the method of system dynamics as well as wrote the manuscript. Peng $\mathrm{Li}$ was responsible for data collection and proofreading of the manuscript. 


\section{Disclosure statement}

There is no competing financial, professional, or personal interest from other parties.

\section{References}

Ameyaw, E. E., Parn, E., Chan, A. P. C., Owusu-Manu, D.-G., Edwards, D. J., \& Darko, A. (2017). Corrupt practices in the construction industry: Survey of Ghanaian experience. Journal of Management in Engineering, 33(6), 05017006.

https://doi.org/10.1061/(ASCE)ME.1943-5479.0000555

Boudreaux, C. J., Nikolaev, B. N., \& Holcombe, R. G. (2018). Corruption and destructive entrepreneurship. Small Business Economics, 51(1), 181-202. https://doi.org/10.1007/s11187-017-9927-X

Brown, J., \& Loosemore, M. (2015). Behavioural factors influencing corrupt action in the Australian construction industry. Engineering Construction and Architectural Management, 22(4), 372-389. https://doi.org/10.1108/ECAM-03-2015-0034

Chan, A. P. C., \& Owusu, E. K. (2017). Corruption forms in the construction industry: Literature review. Journal of Construction Engineering and Management, 143(8), 04017057. https://doi.org/10.1061/(ASCE)CO.1943-7862.0001353

Deng, F., Liu, G., \& Jin, Z. (2013). Factors formulating the competitiveness of the Chinese construction industry: Empirical investigation. Journal of Management in Engineering, 29(4), 435-445.

https://doi.org/10.1061/(ASCE)ME.1943-5479.0000161

Di, X., \& Ji, Y. (2012). Engineering corruption: formation mechanism and prevention strategy. Theoretical Exploration, 2012(4), 48-51, 61.

Feng, Q., Shi, X.-j., \& Xu, W. (2015). Power rent-seeking governance in safety supervision system of projects: Based on evolutionary game model among the subjects. Chinese Journal of Management Science, 23(Special Issue), 9-14.

Feng, Q., Shi, X., \& Zhang, J. (2019). Influence of rent-seeking on safety supervision in Chinese construction: Based on a simulation technology. Technological Forecasting and Social Change, 138, 1-9. https://doi.org/10.1016/j.techfore.2018.10.016

Fernandez-Dengo, M., Naderpajouh, N., \& Hastak, M. (2013). Risk assessment for the housing market in Mexico. Journal of Management in Engineering, 29(2), 122-132.

https://doi.org/10.1061/(ASCE)ME.1943-5479.0000128

Goldie-Scot, H. (2008). Briefing: Corruption in construction in developing countries. Proceedings of the Institution of Civil Engineers-Municipal Engineer, 161(4), 211-213.

https://doi.org/10.1680/muen.2008.161.4.211

Guo, S., Zhang, P., \& Yang, J. (2018). System dynamics model based on evolutionary game theory for quality supervision among construction stakeholders. Journal of Civil Engineering and Management, 24(4), 318-330.

https://doi.org/10.3846/jcem.2018.3068

Huang, D., \& Chen, L. (2012). Analysis and countermeasure of government rent-seeking behavior in large-scale project construction. Seeker, 2012(10), 205-207, 270.

Iqbal, N., \& Daly, V. (2014). Rent seeking opportunities and economic growth in transitional economies. Economic Modelling, 37, 16-22. https://doi.org/10.1016/j.econmod.2013.10.025

Kenny, C. (2009). Transport construction, corruption and developing countries. Transport Reviews, 29(1), 21-41.

https://doi.org/10.1080/01441640802075760
Kyriacou, A. P., Muinelo-Gallo, L., \& Roca-Sagales, O. (2015). Construction corrupts: empirical evidence from a panel of 42 countries. Public Choice, 165(1-2), 123-145.

https://doi.org/10.1007/s11127-015-0297-0

Le, Y., Shan, M., Chan, A. P. C., \& Hu, Y. (2014). Overview of corruption research in construction. Journal of Management in Engineering, 30(4), 02514001.

https://doi.org/10.1061/(ASCE)ME.1943-5479.0000300

Li, Y. (2009). Investigation of rent-seeking in construction project and process of supervision [Master thesis]. Beijing Jiaotong University, Beijing.

Liu, T., Huang, W., Xu, W., \& Wu, Q. (2010). Equilibrium strategies of rent-seeking games of developer based on improved Tullock model. Journal of Tongji University. Natural Science, 38(12), 1851-1856.

Mei, T., Wang, Q., Xiao, Y., \& Yang, M. (2017). Rent-seeking behavior of BIM-and IPD-based construction project in China. Engineering Construction and Architectural Management, 24(3), 514-536. https://doi.org/10.1108/ecam-11-2015-0178

Owusu, E. K., Chan, A. P. C., \& Shan, M. (2017). Causal factors of corruption in construction project management: An overview. Science and Engineering Ethics, 25(1), 1-31.

https://doi.org/10.1007/s11948-017-0002-4

Qin, L. (2017). Study on rent seeking of bidding and system supervision in construction project [Master thesis]. Chongqing University, Chongqing.

Roca, C. P., Cuesta, J. A., \& Sánchez, A. (2009). Evolutionary game theory: Temporal and spatial effects beyond replicator dynamics. Physics of Life Reviews, 6(4), 208-249. https://doi.org/10.1016/j.plrev.2009.08.001

Shiwei, W. A. N., Yugui, C. A. O., \& Zhongzhi, Y. (2006). Game analysis of rent-seeking of engineering supervisors based on principal-agents. Industrial Engineering Journal, 9(4), 46-48, 59.

Snaith, M. S., \& Khan, M. U. (2008). Deleterious effects of corruption in the roads sector. Proceedings of the Institution of Civil Engineers-Transport, 161(4), 231-235. https://doi.org/10.1680/tran.2008.161.4.231

Sohail, M., \& Cavill, S. (2008). Accountability to prevent corruption in construction projects. Journal of Construction Engineering and Management, 134(9), 729-738. https://doi.org/10.1061/(ASCE)0733-9364(2008)134:9(729)

Shurong, Z., \& Miao, P. (2012). Rent-seeking behaviors analysis in engineering supervision based on the game theory. Systems Engineering Procedia, 4, 455-459. https://doi.org/10.1016/j.sepro.2012.01.010

Tabish, S. Z. S., \& Jha, K. N. (2011). Analyses and evaluation of irregularities in public procurement in India. Construction Management and Economics, 29(3), 261-274. https://doi.org/10.1080/01446193.2010.549138

Tullock, G. (2001). Efficient rent-seeking. In A. A. Lockard, \& G. Tullock (Eds), Efficient rent-seeking (pp. 3-16). Springer. https://doi.org/10.1007/978-1-4757-5055-3_2

Tullock, G. (2005). The rent-seeking society (The Selected Works of Gordon Tullock, Vol. 5). Liberty Fund.

Wang, B., \& Cheng, Y. (2013). Project management issues analysis based on rent-seeking theory. Journal of Engineering Management, 27(1), 34-38.

Wang, B., Xu, Y., \& Li, Z. (2005). A dynamic game analysis on disposal of rent-seeking phenomina with incomplete information. Systems Engineering, 23(10), 81-85.

Wang, X., Zhao, H., \& Yu, G. (2008). The countermeasure study on rent-seeking of supervision in engineering construction fields. Soft Science, 22(3), 96-99. 
Wu, Y., \& Peng, F. (2013). Contractor's rent-seeking game in different stages of construction. Engineering Journal of Wuhan University, 46(6), 780-783.

Xiang, P., \& Ren, H. (2010). Behavioural game analysis for three participants in construction project based on theory of information asymmetries. Engineering Sciences, 2010(9), 101-106.

Xiang, P.-c., Kong, D.-p., \& Liu, C.-y. (2009). Behavioral game analysis for participants in construction project. Mathematics in Practice and Theory, 39(10), 83-89.

Xie, S. (2007). Economic game theory (3rd ed.). Fudan University Press.

Yang, R. J., Jayasuriya, S., Gunarathna, C., Arashpour, M., Xue, X., \& Zhang, G. (2018). The evolution of stakeholder management practices in Australian mega construction projects. Engineering Construction \& Architectural Management, 25(6), 690-706. https://doi.org/10.1108/ECAM-07-2016-0168

Zhang, B., Le, Y., Xia, B., \& Skitmore, M. (2017). Causes of business-to-government corruption in the tendering process in China. Journal of Management in Engineering, 33(2), 05016022 .

https://doi.org/10.1061/(ASCE)ME.1943-5479.0000479 